\title{
Developing a qualitative framework for analysis of student journals
}

\author{
$N$ Findlay, $S$ Dempsey and H Warren-Forward
}

\begin{abstract}
School of Health Sciences, Hunter Building, University of Newcastle, Callaghan, New South Wales 2308, Australia.
Correspondence naomi.findlay@newcastle.edu.au
\end{abstract}

\begin{abstract}
Learning from work is an important aspect of student and professional life when working within the health profession. Personal journals are one way that health professionals are able to document their experiences. ${ }^{1}$ These journals also hold a wealth of information about the student experience on placement. ${ }^{2}$ To analyse the content of journals a qualitative research analytical method is required.

There are many different methodological underpinnings or approaches within qualitative research and it is important that the researchers consider their own world view and the context of the research and the data to be evaluated when selecting a qualitative methodology to utilise.

This paper discusses an overview of the process of choosing a qualitative framework for the analysis of the descriptions contained within student personal journals. The paper describes the development and validity checking of a coding or sourcebook for qualitative descriptive analysis of student personal journals.
\end{abstract}

Keywords: analysis frameworks, personal journals, qualitative analysis.

\section{Introduction}

When working as a health professional, some of the most valuable lessons are learned from interactions with patients, carers and colleagues. These same interactions can assist the professional and personal development of undergraduate health science students during professional placement within a clinical facility. Personal journaling is one way that undergraduate health students can describe and reflect on these day to day events, interactions and experiences, and the insights and experiences recorded in the journals can provide a wealth of information about the experiences that were meaningful for the students while on placement. ${ }^{2}$ The descriptive or professional situational content of the journal can also provide feedback that can be used to shape undergraduate curriculum and provide essential feedback to professional placement sites.

Radiation therapy (RT) students at an Australian university have completed personal development journals during their professional placements within radiation oncology treatment centres (ROTC) for over 15 years. The contents of these journals have not until recently been formally investigated for the insight they hold into the specific clinical experience of undergraduate RT students while on professional placement.

Recent work by the authors, ${ }^{3,4}$ has developed and validated reflective analysis measures that assess the level of reflection found in the writing of students. The authors have validated reflective measures on both freeform and short form guided reflective writing. Their analysis of RT students' reflective journals identified that, while many RT students are able to write reflectively, few reach the highest level of critical reflection. ${ }^{3}$

However, the evaluation of reflective writing is not an analysis of the specific professional situation that students reflect about. To evaluate what students reflect about a separate descriptive analysis is required that seeks to describe the content or themes of their reflective writing. By doing this we will be able to assess the level of reflection for specific professional situations.
Qualitative descriptive analysis provides a framework where personal journals can be analysed for the written descriptors that they contain. The flexible nature of qualitative descriptive analysis research makes it a suitable method to understand the meaning or interpretation of subjective experiences. ${ }^{5}$ However, it is this flexible and fluid nature of qualitative descriptive analysis research that lends itself to criticism due to the perceived lack of reliability, validity and rigid rules..$^{5-7}$

A sample of 97 personal journals, completed by RT students over three consecutive years of the undergraduate RT program, has been selected to undergo qualitative analysis. Analysis of these journals will allow a rich description of the issues that undergraduate RT students feel impact on them during professional placement to be explored. In doing qualitative research and qualitative data analysis it is important for researchers to consider which qualitative methodological framework will be used to for their study, as the qualitative methodology will influence the processes and outcomes of the research project. ${ }^{5,6,8,9}$

This paper aims to:

1 Provide an overview of the process of choosing a qualitative framework for the analysis of the professional or developmental content in student journals.

2 Describe the development and validity checking of a coding or sourcebook for the analysis of student journals to increase the reliability and trustworthiness of the outcomes.

\section{Choosing the qualitative framework}

There are many qualitative disciplines or frameworks that can be applied to research settings in health care. Some have methodological underpinnings that make them more or less suited to each context depending on the sample and the phenomenon being studied. Popular methodologies in qualitative research that may be considered for the analysis of RT students' journals include: phenomenology, narrative inquiry, grounded theory, ethnography and qualitative descriptive analysis (QDA). While each of 
Table 1: Comments from the reflection pre-action bracketing exercise.

\begin{tabular}{|l|l|}
\hline Reflection & How do I see this affecting my reading? \\
\hline $\begin{array}{l}\text { Having } 10 \text { years clinical experience in } \\
\text { radiation therapy has left me with quite a } \\
\text { host of clinical knowledge, }\end{array}$ & $\begin{array}{l}\text { It could be in a positive manner by allowing an easier understanding of the situations described by the students in } \\
\text { their journals and enabling me to bridge the terminology gap more readily in my reading of data. However I must be } \\
\text { careful not to allow my knowledge to maybe impede on the experience as described by the student in relation to, } \\
\text { me making a decision whether I think that is technically right, realistically true, technically possible or professional } \\
\text { appropriate etc. At this early stage of the bracketing process, acknowledging that this exists and the potential } \\
\text { problems with it is my only way forward. Dealing with it as the first instance of it arises in analysis will be a great } \\
\text { challenge. }\end{array}$ \\
\hline $\begin{array}{l}\text { Having worked with students for so long } \\
\text { has given me many ideas and thoughts } \\
\text { about students within clinical centres } \\
\text { may affect my interpretation of the } \\
\text { journals }\end{array}$ & $\begin{array}{l}\text { In reality all that I do with students and all that I have experienced with student could have a profound effect on } \\
\text { the transformation that takes place as I begin data analysis. Maybe if I read a situation that can be related to an } \\
\text { experience I may have had with a student, the feelings that are attached could directly affect my interpretation of } \\
\text { the description given from the participant. In those cases I can only think that acknowledging the feelings, recalling } \\
\text { the situation and describing how I am going to set these feelings aside, eg. Visualisation or discussion with a } \\
\text { colleague or a reflective entry might manage the process. Another option may be to seek external objective input on } \\
\text { the diary entry as a form of external validation. }\end{array}$ \\
\hline
\end{tabular}

these have their own philosophical perspective, all use naturally descriptive and/or interpretative data analysis methods to analyse the data collected.

\section{Qualitative descriptive analysis}

Qualitative descriptive analysis (QDA) is underpinned by naturalistic enquiry and is a common form of data analysis in qualitative inquiry in practice fields. ${ }^{10}$ In QDA, the researcher is not trying to describe events in a way that follows a specific research philosophy, like ethnography or phenomenology research. Instead the researcher seeks to describe events, purely as the participant has reported they occurred. A wide range of techniques can be used for the data collection, sampling and analysis in a QDA study. ${ }^{10,11}$ Data collection techniques can include focus groups, journals, interviews or even observation. ${ }^{10,12,13}$ The subsequent sampling may be selected using convenience or purposeful sampling techniques. ${ }^{14,15}$

Qualitative descriptive analysis is often overlooked as a research method in its own right. Sandelowski ${ }^{10,11}$ describes the characteristics of a QDA as often working with the surface of the words rather than their deeper meaning, with little interpretation required. A qualitative descriptive analysis is often used when a straightforward answer, with little interpretation from an imposed theoretical philosophy, is required.

In terms of the requirements for this research, i.e. the descriptions of events recorded in personal journals, a qualitative descriptive analysis is an appropriate methodology that will yield a straight descriptive summary of the information evident in the journals. A QDA is the method of choice for this study, working within the confines of the predetermined data set.

\section{Development of a qualitative sourcebook}

One analysis technique often utilised in QDA is a qualitative content analysis. ${ }^{10}$ Qualitative content analysis can be defined as a systematic analysis of text to describe the content and visibly obvious components of the data. ${ }^{16}$ It requires the systematic reading and coding of text, images or even symbolic matter. ${ }^{9}$ Essential to any content analysis is the formulation of a good sourcebook and worksheet with the accompanying dictionaries. ${ }^{8}$

A code or sourcebook can be a hard copy or electronic resource that provides the person evaluating and perhaps coding the data with a set of rules, variables and description of the variables. ${ }^{8}$ Sourcebooks can include general coding instructions, information on each coding unit/sub-unit to be coded for and dictionaries to assist the coding process. The dictionaries can range from those containing information emergent from the text to be coded, to author created dictionaries that contain words, phrases and definitions that assist the coder in recognising portions of text that belong to the units and subunits being coded for. ${ }^{8.9}$ A worksheet can also be in many different mediums and allows the results of the coding to be documented. ${ }^{8}$

A coding system and sourcebook should provide a complete and unambiguous guide to facilitate the coding process of the personal journals, allowing the coding process to be replicated elsewhere with rigour. ${ }^{9}$ A good sourcebook aims to minimise the difference between individual coders during the content analysis stage.

Creating a coding system including an original sourcebook and worksheet is a very involved process. The following sections of this paper will describe the method used for the development of the sourcebook for analysis of the 97 RT personal journals mentioned above and the result of each step in the process.

\section{Bracketing in qualitative analysis}

All researchers and practitioners carry biases of some form. For example, a bias may stem from previous experience in a given field or personal perspective about a specific topic. In qualitative research, biases have the potential to impact on the research process and findings, either at a conscience or subconscious level. ${ }^{5-7}$ Bracketing is an exercise that can be undertaken to minimise the possible impact biases can have on the qualitative research process. Bracketing involves identifying and placing on hold everyday assumptions, beliefs and previous personal experiences, in relation to the phenomenon under study. ${ }^{17,18}$ It provides a way for the researcher to avoid imposing these elements on the experience of the participants, minimising the possibility of the researchers' preconceived ideas guiding them as they collect and analyse the data. ${ }^{19} \mathrm{~A}$ framework to guide bracketing where the researcher reflects pre-action, in-action and on-action, can be used to assist the researcher in becoming aware of any assumptions they may hold prior to analysis, emotional influences they may feel during analysis and as an evaluative process after analysis. If bracketing identifies issues that may bias the analysis in the pre and in action phases, strategies such as visualisation where the researcher visualises placing the issues in imaginary brackets can be incorporated as a means to isolate them from the analysis. It is important to acknowledge that the process of bracketing is one that must be learned and skill is gained as the researcher gains experience. ${ }^{20}$ 
Table 2: Initial raw emergent categories and subcategories.

\begin{tabular}{|c|c|c|c|}
\hline Major category & Sub category & Major category & Subcategory \\
\hline Resources & $\begin{array}{c}\text { Rosters } \\
\text { Practical issues } \\
\text { Lack of planning access } \\
\text { Lack of hands on practice } \\
\text { Feeling like department fodder }\end{array}$ & Teamwork & $\begin{array}{c}\text { Teamwork } \\
\text { Conflict with staff } \\
\text { Welcome by staff } \\
\text { Gaining staff trust } \\
\text { Student/staff relationship } \\
\text { Working with docs } \\
\text { Staff expectations }\end{array}$ \\
\hline Personal development & $\begin{array}{c}\text { Becoming confident } \\
\text { Enjoyed prac } \\
\text { Admiration of RTs } \\
\text { Confronting own emotions } \\
\text { Happy with progress } \\
\text { Found prac challenging } \\
\text { Nervous about prac } \\
\text { Expectations while on clinical placement } \\
\text { Confronting own emotions about }\end{array}$ & The patient & $\begin{array}{c}\text { Quality of life } \\
\text { Empathy for parents and family } \\
\text { Parent relationship } \\
\text { Holistic patient care } \\
\text { Patient confidence levels } \\
\text { Patient pathway }\end{array}$ \\
\hline Professional & $\begin{array}{c}\text { Right career choice } \\
\text { Becoming professional } \\
\text { Thinking about after graduation } \\
\text { RT professional role } \\
\text { Ethical dilemma } \\
\text { Career uncertainty } \\
\text { Emerging work area preference } \\
\text { Job satisfaction }\end{array}$ & Reflective learning & $\begin{array}{l}\text { Critical thinking skills } \\
\text { Evaluating uni program } \\
\text { Critiquing technique } \\
\text { Comparing to previous prac or } \\
\text { Demonstrating problem solving } \\
\text { Critiquing equipment } \\
\text { Critical of centre }\end{array}$ \\
\hline Assessment & $\begin{array}{l}\text { Competencies and assessment } \\
\text { Accepting criticism } \\
\text { Department expectations of student }\end{array}$ & Technical learning & $\begin{array}{c}\text { Assessing abilities and learning } \\
\text { Expanding technical knowledge } \\
\text { Theory practice gap } \\
\text { Awareness of side effects } \\
\text { Expanding duties }\end{array}$ \\
\hline
\end{tabular}

\section{Sourcebook development}

The development of the sourcebook was conducted over the following steps.

Step 1: Prior to reading any of the journals the researcher undertook "reflection pre-action" bracketing. During this process the researcher reflected upon on issues that may arise within the journal that they had an opinion on or bias about that may impact on the coding. These comments and thoughts were entered into an Excel spread sheet. Table 1 illustrates examples of these comments from the "Reflection pre-action" bracketing exercise.

Step 2: All journals were read by the researcher to familiarise the researcher with their overall content, making memos on the general feeling of the journals. This comment was then recorded in a few words on the hard copy cover of the journal entry. These comments were also entered into an Excel spreadsheet.

Step 3: The journals were then reread a second time by the researcher. During this reading the journals were explored for the topics or categories that were present in the descriptive content of the journals. As the researcher identified a topic or category the section of text was highlighted and the topic name was placed in the right hand margin of the journal.

No priori of categories or topics were used to guide the coding process or prompt the researcher for what to look for within the personal journals. All categories identified were those that emerged from the data. While the researcher was aware of content analysis completed within other health professions, bracketing was used and this knowledge was set aside to minimise the chance of emergent themes and content from the data being bias or led. When the reading and coding reached a stage where for five to six
Table 3: Final unique and mutually exclusive emergent categories and subcategories.

\begin{tabular}{|c|c|}
\hline Major category & Subcategory \\
\hline \multirow{4}{*}{$\begin{array}{l}\text { 1. Clinical } \\
\text { environment }\end{array}$} & 1 Department structure \\
\hline & 2 Life style \\
\hline & 3 Equipment \\
\hline & 4 Other \\
\hline \multirow{8}{*}{$\begin{array}{l}\text { 2. Personal } \\
\text { development in } \\
\text { the profession }\end{array}$} & 5 Professional growth \\
\hline & 6 Emotions \\
\hline & 7 Enjoyment/Job satisfaction \\
\hline & 8 Communication \\
\hline & 9 Confidence \\
\hline & 10 Judgments \\
\hline & 11 Technical learning \\
\hline & 12 Other \\
\hline \multirow{2}{*}{$\begin{array}{l}\text { 3. View of the } \\
\text { profession }\end{array}$} & 13 Teamwork \\
\hline & 14 Other \\
\hline \multirow{4}{*}{ 4. The patient } & 15 Quality of life \\
\hline & 16 Patient pathways \\
\hline & 17 Building relationships \\
\hline & 18 Other \\
\hline
\end{tabular}

consecutive journals no new categories or topics emerged from the data, the reading and coding was stopped.

Step 4: For each journal the identified topics were then entered into an Excel ${ }^{\mathrm{TM}}$ spreadsheet along with supporting quotations and their location within the text, allowing for an audit trail back to the 
Table 4: Summary of major priori of themes evidenced from the literature of student professional placements in various health professions.

\begin{tabular}{|c|c|c|c|c|c|c|c|}
\hline Category or topic identified & $\begin{array}{c}\text { Mackenzie }^{21} \\
\text { (OT) }\end{array}$ & Patton $^{15}$ (N) & Landeen $^{22}(\mathrm{n})$ & $\begin{array}{c}\text { Williams }^{23} \\
\text { (PT) }\end{array}$ & $\begin{array}{l}\text { Williams }^{24} \\
\text { (PT) }\end{array}$ & $\begin{array}{l}\text { Williams }^{25} \\
\text { (PT) }\end{array}$ & Pikala $^{26}(\mathrm{M})$ \\
\hline Expectations while on clinical & $x$ & & & & & & \\
\hline Patient relationship & $x$ & $x$ & $x$ & & $x$ & $x$ & $x$ \\
\hline Long term professional issues & $x$ & & & & $x$ & & \\
\hline Meaning of final placement on career & $x$ & & & $x$ & & & \\
\hline Increase knowledge and skill & & $x$ & $x$ & $x$ & $x$ & $x$ & \\
\hline Theory - practice connection & & & & $x$ & & $x$ & $x$ \\
\hline Problem solving skill and critical appraisal & & & & $x$ & $x$ & $x$ & \\
\hline
\end{tabular}

OT is Occupation Therapy, $\mathrm{N}$ is nursing, PT is Physiotherapy. $\mathrm{M}$ is medicine. The shaded categories are those that are present in the final categpry and subcategory framework

\begin{tabular}{|c|c|c|c|c|}
\hline \multicolumn{5}{|c|}{ QDA Sourcebook Journal Analysis } \\
\hline Coder name: & \multicolumn{4}{|c|}{ At the top of the coding worksheet place your name in the provided space } \\
\hline Participant name: & \multicolumn{4}{|c|}{$\begin{array}{l}\text { At the top of the worksheet place the participant ID for the journal you are about to code eg } \\
2003-10\end{array}$} \\
\hline Worksheet: & \multicolumn{4}{|c|}{ A new worksheet is to be used for each journal coded. } \\
\hline At completion: & \multicolumn{4}{|c|}{ After completing the coding, all journals and worksheets are to be returned to the researcher } \\
\hline Category Groups & Clinical environment & $\begin{array}{l}\text { Personal } \\
\text { development in the } \\
\text { profession }\end{array}$ & $\begin{array}{l}\text { View of the } \\
\text { profession }\end{array}$ & The patient \\
\hline \multirow{8}{*}{ Key themes } & 1. Department structure & 5. Professional growth & 13. Teamwork & 15. Quality of life \\
\hline & 2. Lifestyle & 6. Emotions & 14. Other & 16. Patient pathways \\
\hline & 3. Equipment & $\begin{array}{l}\text { 7. Enjoyment/Job } \\
\text { satisfaction }\end{array}$ & & $\begin{array}{l}\text { 17. Building } \\
\text { relationships }\end{array}$ \\
\hline & 4. Other & 8. Communication & & 18. Other \\
\hline & & 9. Confidence & & \\
\hline & & 10. Judgements & & \\
\hline & & 11. Technical learning & & \\
\hline & & 12. Other & & \\
\hline \multirow{4}{*}{$\begin{array}{l}\text { Coding guidel } \\
\text { dictionary. }\end{array}$} & \multicolumn{4}{|c|}{ The following pages contain details of the four groups and subsequent 18 categories. } \\
\hline & \multirow{2}{*}{\multicolumn{4}{|c|}{$\begin{array}{l}\text { The first column details the group and specific category, the column headed Concepts } \\
\text { provides ideas as to what concepts, topics or subjects may be found in each category. } \\
\text { The final column titled, Words, Phrases and Comments, provides some words that may be } \\
\text { associated with a concept, quotes that demonstrate a concept from the journal, and } \\
\text { instructions that will assist coding text in each category. }\end{array}$}} \\
\hline & & & & \\
\hline & \multicolumn{4}{|c|}{$\begin{array}{l}\text { The concepts, words and phrases provided in this guide are not exhaustive. If you identify } \\
\text { elements of the text that represent any of the } 18 \text { categories regardless of whether it is } \\
\text { mentioned in the concept and phrases guide, code it accordingly. }\end{array}$} \\
\hline \multirow{6}{*}{$\begin{array}{l}\text { Coding } \\
\text { instructions: }\end{array}$} & \multicolumn{4}{|c|}{$\begin{array}{l}\text { Before reading each journal, label a new QDA worksheet with your name and the participant } \\
\text { number found at the top right hand corner of the journal. Then read the journal in full. Re-read } \\
\text { and code the journal one, paragraph at a time. }\end{array}$} \\
\hline & \multicolumn{4}{|c|}{$\begin{array}{l}\text { As you read each journal identify words, phrases or concepts that represent any of the } 18 \\
\text { categories listed above. }\end{array}$} \\
\hline & \multicolumn{4}{|c|}{$\begin{array}{l}\text { Find the row that the identifed category occupies on the worksheet then in the first column } \\
\text { annotate the page and paragraph that the text is located in. }\end{array}$} \\
\hline & \multicolumn{4}{|c|}{$\begin{array}{l}\text { For example if the text is on page } 1 \text { paragraph } 4 \text {, write down } 1.4 \text {. Additionally highlight the text } \\
\text { coded and also document the category number in the right hand margin of the journal. }\end{array}$} \\
\hline & \multicolumn{4}{|c|}{ Each unit (phrase, sentence, paragraph) can only represent one category on the worksheet. } \\
\hline & \multicolumn{4}{|c|}{$\begin{array}{l}\text { ff a category is identified more than once simply repeat the documentation process as } \\
\text { described above each time you identify it in the text. }\end{array}$} \\
\hline
\end{tabular}

Figure 1: Rules governing the QDA coding process (excerpt from Sourcebook) 


\begin{tabular}{|c|c|c|}
\hline $\begin{array}{l}\text { Clinical } \\
\text { Environment }\end{array}$ & \multicolumn{2}{|c|}{$\begin{array}{l}\text { The section on clinical structure is about how the structure of the clinical placement } \\
\text { affected the student's experience. The key themes include Department structure, } \\
\text { lifestyle effects and equipment. Included in each of these key themes may be concepts }\end{array}$} \\
\hline \multirow{15}{*}{$\begin{array}{l}\text { 1. Department } \\
\text { Structure }\end{array}$} & Concepts & Words, Phrases, Comments \\
\hline & \multirow{3}{*}{ Rosters } & $\begin{array}{l}\text { I was excited to see I was rostered to different departments within the } \\
\text { hospital }\end{array}$ \\
\hline & & I would have liked more time in the planning room \\
\hline & & this allowed me to get use to it rather than constantly rotating \\
\hline & \multirow{2}{*}{ Workload } & $\begin{array}{l}\text { I was surprised to see how many patients were put through... they (RTs) } \\
\text { were constantly run of their feet. }\end{array}$ \\
\hline & & They are always so busy \\
\hline & \multirow{3}{*}{$\begin{array}{l}\text { Lack of planning } \\
\text { access }\end{array}$} & I did not get much of a chance to practice or do things on the computer \\
\hline & & $\begin{array}{l}\text { I would have liked more time in there (planning) as I don't really think I } \\
\text { gained as much as I could have. }\end{array}$ \\
\hline & & $\begin{array}{l}\text { felt like there was a lot of time with nothing to do ... because l could } \\
\text { not get access to a terminal }\end{array}$ \\
\hline & \multirow{2}{*}{$\begin{array}{l}\text { Accessing } \\
\text { patients and } \\
\text { resources }\end{array}$} & $\begin{array}{l}\text { because there was a PDY, student and therapist, ... the other therapists } \\
\text { spent more time with them (PDY) and kinder gave the more to do }\end{array}$ \\
\hline & & $\begin{array}{l}\text { This concept is where students feel that maybe the staffing, workload or } \\
\text { other departmental factors effected their access to patients and } \\
\text { resources on clinical placement }\end{array}$ \\
\hline & \multirow{3}{*}{$\begin{array}{l}\text { Student } \\
\text { mentoring, } \\
\text { asking } \\
\text { questions }\end{array}$} & I found it difficult to ask questions as they were always so busy \\
\hline & & Its really hard when my buddy is away on RDO \\
\hline & & I wish they had a buddy system...... \\
\hline & $\begin{array}{l}\text { Department } \\
\text { expectations }\end{array}$ & $\begin{array}{l}\text { There were higher expectations of me to show new found knowledge } \\
\text { and apply this knowledge }\end{array}$ \\
\hline
\end{tabular}

Figure 2: Category 'Clinical Environment', subcategory 'Department Structure' description and dictionary extracted from the Sourcebook.

initial data. This process resulted in the collection of eight major categories and 50 subcategories (Table 2).

Step 5: The categories or topics that were identified from all three years of personal journals were then examined holistically for commonalities. The researcher and an independent expert within the field of RT and education reviewed the categories before meeting to brainstorm and collate their ideas. During this session sections of the students' journals were read and discussed as to what category or sub categories they may belong to within the raw framework. This process resulted in overlap and ambiguity across the framework to be identified. This process allowed major categories and subcategories to be defined that were unique and mutually exclusive (Table 3). For each major category, a subcategory of "other" was inserted into the framework. This allows for any topics that are identified within the journals during the QDA that do not fit into the developed framework, to be accounted for in the "other" subcategory.

Step 6: Validity testing - This final category and subcategory framework was then subjected to content and face validity test.

\section{Content validity}

Content validity is used to assess whether the measures are representative of the full domain of measures for a given situation. ${ }^{8,9}$ Content validity testing was undertaken using two methods.

First, the framework of major categories and sub categories was compared to a priori of themes available from the literature from similar studies conducted within the undergraduate health professional setting. The priori of themes used for comparison (Table 4) consists of a list of categories and topics identified in the journals of students undertaking professional placements in the clinical setting for a variety of health professions, including medicine, physiotherapy, occupational therapy and nursing. The researcher examined the framework against this list of themes to explore any commonalities. Table 4, illustrates that although the priori of themes contains no studies undertaken in radiation therapy or medical radiation sciences there was a strong concordance between the priori of themes within the literature and the major categories and subcategories that the framework contains.

Next an independent radiation therapist with extensive experience in the education field was asked to review the category/ subcategory framework from a content validity perspective. This expert was selected due to the range of experiences that they have been exposed to over the years in RT and students' experiences on placement. Based on their personal experience, the RT professional assessed whether the final categories and subcategories resonated with those that they might expect an undergraduate RT student to experience in the clinical setting and was asked to provide feedback accordingly. Feedback indicated that the major categories and subcategories were thought to be extensive and covered all areas of student clinical experience and appropriate to the context of professional placement.

\section{Face validity}

Face validity is a form of testing that examines whether on the "face of things" the sourcebook is going to explore the desired concepts. ${ }^{8}$ For example, in the instance of this study when the face validity check is completed, if the tool has good face validity the person undertaking the assessment will be able to describe the 
context of the study that the framework is to be applied to, without discussion or information from the researcher involved. ${ }^{8,9}$

A second independent content expert with over 10 years experience within the field of RT and student education was selected to undertake this assessment of the framework. They were provided with the framework to review and interviewed by the researcher. During the interview they were asked to describe the setting and context they felt the research was going to be exploring. In this instance, the interview revealed a high level of face validity for the framework with the reviewer able to accurately describe the context for the study to be undertaken.

Step 7: A coding sourcebook was developed for use by independent coders that will undertake the QDA of the journals. It provides the coders with guidelines and details to follow when completing the coding. The sourcebook was created in available word processing software. There are no strict rules to guide the format of the sourcebook or its layout.

The sourcebook provides the coders with a strict framework to follow and reference in order to maintain consistency and rigour during later analysis. The sourcebook incorporates coding instructions, the category/sub-category framework, and a dictionary to guide the coding process. The dictionary was one created from the emergent data, which provided words, phrases and examples for each of the subcategories. Figure 1 illustrates the section of the sourcebook that provides an overview of the category and subcategory framework as well as an explanation of the coding guide and dictionary and full coding instructions. While Figure 2 is an excerpt from the sourcebook for the "Clinical Environment" category, "Department Structure" subcategory. For each category the sourcebook provides an over viewing statement, concepts that may be discussed in the subcategory and words and phrases that may be identified with the text for this subcategory.

\section{Summary}

Qualitative research methods allow researchers to analyse and describe the qualitatively different ways that humans experience and describe life-world events. QDA is an analytical method that can be used to explore the experiences and issues that impact on health science students as documented in student's personal journals.

Integral to the rigour of the research is the selection of an appropriate qualitative methodology. This paper has discussed qualitative descriptive analysis and its suitability to the sample of personal journals being studied.

In the context of a qualitative descriptive analysis, a sourcebook is essential to the content analysis process. Development of a thorough and valid sourcebook will promote quality coder training and inter-coder reliability. Within the context of this study the analysis of the journals using the sourcebook developed and the results of the analysis will be available in a future publication.

\section{The authors \\ Ms Naomi Findlay BAppSc(MRS) \\ Mr Shane Dempsey GradDipClinEpi, GradCert \\ HEd, DipAppSci (MRT) \\ Assoc Prof Helen Warren-Forward BSc PhD}

\section{References}

1 Chapman N, Warren-Forward H, Dempsey S. Workplace diaries promoting reflective practice in radiation therapy. Radiography 2009; 15 (2): 166.

2 Findlay N, Dempsey S, Warren-Forward H. A qualitative analysis of radiation therapy students professional placement journals. Radiography; In Press 27 May 2010.
3 Findlay N. Validation and use of the newcastle reflective analysis tool: a threeyear longitudinal study of RT students reflective journals. Reflective Practice 2010; 11 (1): 83

4 Findlay N, Dempsey S, Warren-Forward H. Development of the Newcastle Reflective Analysis Tool. Focus on Health Professional Education 2009; 11 (1): $32-40$.

5 Liamputtong P. Qualitative Research Methods. 3rd Edition. Melbourne: Oxford University Press, 2009.

6 Liamputtong P. Research Methods in Health: foundation for evidence based practice. 1st Edition. Melbourne: Oxford University Press; 2010.

7 Carpenter C, Suto M. Qualitative Research for occupational and physical therapist: A practical guide. Oxford: Wiley-Blackwell; 2008.

8 Neuendorf K. The Content Analysis Guidebook. California: Sage Publications; 2002.

9 Krippendorff K. Content Analysis An Introduction to its Methodology. California: Sage Publications Inc; 2004.

10 Sandelowski M. Whatever happened to qualitative description? Res Nurs Health, 2000; 23: 334-40.

11 Sandelowski M. What's in a name? Qualitative description revisited. Res Nurs Health 2010; 33: 77-84.

12 Morse J, Richards L. Read me first for a user's guide to qualitative methods. Thousand Oaks, CA: Sage Publications; 2002. xv 262.

13 Morse JM. Conceptual analysis in nursing research: a critical appraisal. Sch Enq Nurs Prac 1996; 10 (3): 253-77.

14 Morse J. Strategies of Intraproject Sampling, in Nursing Research: A Qualitative Perspective. P Munhall, Editor. Jones and Bartlett Publishers: Sudbury; 2006.

15 Patton M. Qualitative Research and Evaluation Methods. Thousand Oaks CA: Sage Publications; 2002.

16 Graneheim U, Lundman B. Qualitative content analysis in nursing research: concepts, procedures and measures to achieve trustworthiness. Nurse Educ Today 2004; 24: 105-12.

17 Morse J, Field P. Qualitative Research Methods for Health Professionals. 2nd Edition. Thousand Oaks CA: Sage Publications; 1995.

18 Lopez K, Willis D. Descriptive versus interpretive phenomenology: The contributions to nursing knowledge. Qualitative Health Research 2004; 14 (5): 726-35.

19 Crotty M. Phenomenology and nursing research. South Melbourne: Churchill Livingstone; 1996. vi 202.

20 Wall C, Glenn S, Mitchinson S, Poole H. Using a reflective diary to develop bracketing skills during a phenomenological investigation. Nurse Res 2004; 11 (4): 20-9.

21 Mackenzie L. Briefing and Debriefing of student fieldwork experiences: exploring concerns and reflecting on practice. Aust Occup Ther J, 2002; 49 (2): 82-92.

22 Landeen J, Byrne C, Brown B, Exploring the lived experiences of psychiatric nursing students through self-reflective journals. J Adv Nurs 1995; 21 (5): $878-85$.

23 Williams R, Wilkins S. The use of reflective summary as a method of obtaining student feedback about entering physical therapy practise. J Phys Therap Edu 1999; 13 (1): 28-33.

24 Williams R, Wessel J. Reflective journal writing to obtain student feedback about their learning during the study of chronic musculoskeletal conditions. $J$ Allied Health 2004; 33 (1): 17-23.

25 Williams R, Wessel J, Gemus M, Foster-Seargant E. Journal writing to promote reflection by physical therapy students during clinical placements. Physiother Theory Pract 2002; 18.

26 Pitkala K, Mantyranta T. Feelings related to first patient experience in medical school: A qualitative study on students' personal portfolios. Patient Education and Counselling 2004; 54: 171-7. 